\title{
PENGARUH TEKNIK RELAKSASI GENGGAM JARI TERHADAP PENURUNAN INTENSITAS NYERI DISMINORE PADA MAHASISWI STIKES BINA GENERASI POLEWALI MANDAR
}

\author{
UMMU KALSUM
}

Dismenore adalah nama medis untuk menstruasi yang disertai dengan kram dan rasa sakit yang berlebihan. Relaksasi genggam jari adalah sebuah tekhnik relaksasi yang sangat sederhana dan mudah dilakukan oleh siapapun yang berhubungan dengan jari tangan serta aliran energi di dalam tubuh kita. Tekhnik genggam jari disebut juga finger hold.

Tujuan penelitian ini adalah untuk mengetahui Pengaruh Teknik Relaksasi Genggam Jari Terhadap Penurunan Intensitas Nyeri Disminore Pada Mahasiswi Stikes Bina Generasi PolewaliMandar.

Penelitian ini merupakan penelitian Eksperimen dengan desain penelitian adalah quasy experiment dengan rancangan pre dan post test. Teknik sampling yang digunakan pada penelitian adalah Consecutive Sampling dengan subjek penelitian sebanyak 12 responden. Dalam penelitian ini pengumpulan data menggunakan lembar observasi, Analisis data menggunakan uji Mc.Nemar Test untuk melihat pengaruh pada satu variabel pengukuran dengan tingkat kemaknaan $\alpha=0,05$.

Hasil pengolahan data yang dilakukan dengan menggunakan analisa data dengan uji McNemar yang menunjukkan ada pengaruh teknik relaksasi genggam jari terhadap penurunan intensitas nyeri disminore pada mahasiswi STIKES BinaGenerasi dengan tingkat signifikan $\mathrm{p}=0,04$.

Kata kunci $\quad$ : Teknik Relaksasi Genggam Jari, Intensitas Nyeri, Disminore.

\section{PENDAHULUAN}

Teknik genggam jari adalah cara yang mudah untuk mengelola emosi dan mengembangkan kecerdasan emosional. Emosi adalah seperti gelombang energi yang mengalir di dalam tubuh, pikiran, dan jiwa. Saat kita merasakan perasaan yang berlebihan, aliran energi di dalam tubuh kita menjadi tersumbat atau tertahan, sehingga akan menghasilkan rasa nyeri atau kemampatan. Di sepanjang jari-jari tangan kita terdapat saluran atau meridian energi yang terhubungkan dengan berbagai organ dan emosi, dengan memegang setiap jari sambil bernafas dalam-dalam, kita dapat memperlancar aliran energi emosional dan perasaan kita untuk membantu pelepasan jasmani dan penyembuhan (Cane, 2013).

Teknik genggam jari ini sangat berguna untuk kehidupan sehari-hari. Saat kita menangis, merasa marah, atau gelisah karena situasi yang sulit, teknik ini dapat membantu kita untuk menjadi lebih tenang dan fokus sehingga kita dapat mengambil tindakan atau respon yang tepat dalam menghadapi situasi tersebut. Tekhnik ini juga dapat dilakukan sebagai meditasi yang diiringi oleh musik, atau dilakukan sebelum tidur untuk melepaskan masalah-masalah yang dihadapi dan membantu tubuh, pikiran, dan jiwa untuk mencapai relaksasi (Cane, 2013).

Relaksasi genggam jari adalah sebuah tekhnik relaksasi yang sangat sederhana dan mudah dilakukan oleh siapapun yang berhubungan dengan jari tangan serta aliran energi di dalam tubuh kita. Tekhnik genggam jari disebut jugafinger hold (Liana,2008).

Setiap individu pernah mengalami nyeri dalam tingkat tertentu. Nyeri merupakan alasan yang paling umum orang mencari perawatan kesehatan.Individu yang merasakan nyeri merasa tertekan atau menderita dan mencari upaya untuk menghilangkan nyeri. Nyeri bersifat subjektif, tidak ada dua individu yang mengalami nyeri yang sama dan tidak ada dua kejadian nyeri yang sama menghasilkan respons atau 
perasaan yang identik pada seorang individu. Nyeri merupakan sumber penyebab frustasi, baik klien maupun bagi tenaga kesehatan.

Dismenore adalah nama medis untuk menstruasi yang disertai dengan kram dan rasa sakit yang berlebihan. Kejadian dismenore merata pada $40-80 \%$ wanita dan $5-10 \%$ wanita mengalami dismenore yang berat dan tidak tertahankan (Morgan \& Hamilton, 2009). French (2005, dalam Ningsih, 2011) menyatakan di Amerika prevalensi dismenore paling tinggi pada usia remaja dengan estimasi $20-90 \%$ dengan nyeri haid berat sebanyak $15 \%$. Sedangkan di Malaysia prevalensi dismenore pada remaja sebanyak 62,3\% ( Liliwati, Verna \& Khairani, 2007, dalam Ningsih, 2011). Dismenore primer terjadi akibat endometrium mengandung prostaglandin dalam jumlah yang tinggi selama fase luteal dalam siklus menstruasi. Hal ini menyebabkan kontraksi miometrium yang kuat dan mampu menyempitkan pembuluh darah yang mengakibatkan iskemia, disintegrasi endometrium, perdarahan dan nyeri. Dismenore primer muncul berupa serangan ringan, kram pada perut bagian bawah, bersifat spasmodik yang dapat menyebar kepunggung atau paha bagian dalam.

Menurut World Health Organization (WHO) Angka kejadian nyeri menstruasi di dunia sangat besar. Lebih dari $50 \%$ perempuan di setiap Negara mengalami nyeri menstruasi. Di Amerika angka persentasenya sekitar $60 \%$ dan di Swedia sekitar 72\%, sementara di Indonesia angkanya diperkirakan $55 \%$ perempuan usia produktif yang tersiksa oleh nyeri selama menstruasi. Angka kejadian (prevalensi) nyeri menstruasi berkisar 4595\% di kalangan wanita usia produktif. Walaupun pada umumnya tidak berbahaya, namun seringkali dirasa mengganggu bagi wanita yang mengalaminya. Derajat nyeri dan kadar gangguan tentu tidak sama untuk setiap wanita. Ada yang masih bias bekerja (sesekali sambil meringis), adapula yang

\section{METODE PENELITIAN Jenis dan Metode Penelitian}

tidak sanggup beraktifitas karena nyerinya (Proverawati, 2009).

Di Amerika serikat,prevalensi dismenore diperkirakan 45-90\%. Tingginya angka ini diasumsikan dari berbagai gejala yang belum dilaporkan. Banyak wanita yang membeli obat sendiri dan tidak berkunjung ke dokter. Studi longitudinal dari swedia melaporkan dismenore pada $90 \%$ wanita yang berusia kurang 19 tahun dan 67\% wanita yang berusia 24 tahun. Sedang hasil penelitian yang dilakukan oleh gunawan 2002 di SLTP Jakarta menunjukkan bahwa pada dismenorea primer sebanyak $76,6 \%$. Dismenore yang muncul pada usia 12 tahun yaitu sebanyak 46,7\%.

Hasil penelitian yang dilakukan oleh tantri heriani di SMP Negeri 2 kayen kabupaten Pati didapatkan siswi yang mengalami dismenore sebanyak 67 $(74,4 \%)$ dari jumlah 90 siswi yang sudah menstruasi . Sedangkan di Mts ASsyafi'iyah dari 72 siswi, yang sudah menstruasi sebanyak 57 orang dan yang mengalami dismenore sebanyak 45 $(78,9 \%)$ (Tantri heriani,2014). negaranegara berkembang.

Berdasarkan data di Indonesia angka kejadian dismenorea sebesar 64,25\% yang terdiri dari $54,89 \%$ dismenorea primer dan 9,36\% dismenorea sekunder (Info sehat, 2008). Angka kejadian dismenorea tipe primer di Indonesia adalah sekitar 54,89\%, sedangkan sisanya adalah penderita dengan tipe sekunder.

Berdasarkan studi pendahuluan yang di lakukan pada tanggal 22 Juni 2017 di Kampus STIKES BINA GENERASI di dapatkan mahasiswi yang mengalami nyeri disminore dari semester I-VIII berjumlah 20 orang dengan skala nyeri yang berbeda-beda.

Dari uraian latar belakang diatas, maka peneliti tertarik untuk melakukan penelitian yang berjudul Pengaruh Teknik Relaksasi Genggam Jari Terhadap Penurunan Intensitas Nyeri Disminore Pada Mahasiswi Stikes Bina Generasi Polewali Mandar.

Desain Penelitian ini yaitu quasy experimet design (eksperimen semu) dengan pendekatan rancangan penelitian 
One Group Pretest-Postest tanpa menggunakan kelompok Control (pembanding). Penelitian ini dilakukan dengan mengobservasi intensitas nyeri disminore sebelum dan sesudah diberi perlakuan.

\section{Lokasi dan Waktu Penelitian}

\section{Lokasi dan Waktu Penelitian}

Penelitian ini dilakukan di Kampus STIKes Bina Generasi Polewali Mandar pada bulan Juni - Agustus Tahun 2017

\section{Populasi dan Sampel}

Populasi dalam penelitian ini adalah Mahasiswi Stikes Bina Generasi Polewali Mandar. Dalam penelitian ini, sampel yang diambil berdasarkan kriteria-kriteria :

1. Kriteria inklusi

Kriteria inklusi merupakan karakteristik umum subjek penelitian

HASIL DAN PEMBAHASAN

\section{Hasil Penelitian}

Tabel 4.2.1.1 pada populasi target dan sumber (Agus Riyanto, 2011).

a. Mahasiswi yang bersedia untuk dijadikan sampel penelitian.

b. Mahasiswi yang mengalami dismenore denganskala nyeri 3 sampai 9

2. Kriteria eksklusi

Sementara kriteria eksklusi merupakan kriteria dari subjek penelitian yang tidak boleh ada, dan jika subjek mempunyai criteria eksklusi maka subjek harus dikeluarkan dari penelitian (Agus Riyanto, 2011).

a. Mahasiswi yang tidak bersedia untuk dijadikan sampel penelitian.

b. Mahasiswi yang skala nyeri disminore 1-2

Distribusi Responden Berdasarkan Karakteristik Umur

Pada

Mahasiswi STIKes Bina Generasi Polewali Mandar Tahun 2017

\begin{tabular}{|l|l|l|l|}
\hline No & Umur & N & Persent (\%) \\
\hline 1. & 22 & 10 & $50 \%$ \\
\hline 2. & 21 & 10 & $50 \%$ \\
\hline & Jumlah & 20 & $100 \%$ \\
\hline
\end{tabular}

Sumber :Data Primer 2017

Berdasarkan umur didapatkan bahwa umur 22 tahun yaitu 10 responden $(50 \%)$

Tabel 4.2.1.12 kemudian 21 tahun yaitu 10 responden $(50 \%)$.

\section{Distribusi Responden Berdasarkan Karakteristik Kelas}

Pada Mahasiswi di STIKES BINA GENERASI Polewali Mandar

\begin{tabular}{|l|l|l|l|}
\hline No & Kelas & N & Persent (\%) \\
\hline 1. & Semester IV & 10 & $50 \%$ \\
\hline 2. & Semester II & 10 & $50 \%$ \\
\hline & Jumlah & 20 & $100 \%$ \\
\hline
\end{tabular}

Sumber :Data Primer 2017

Berdasarkan kelas dari 20 respoden mempunyai jumlah yang sebanding yaitu didapatkan bahwa adalah kelas Semester IV tahun yaitu 10 responden $(50 \%)$ dan kelas Semester II yaitu 10 responden $(50 \%)$

Tabel 4.2.2.1

Distribusi Responden Berdasarkan Karakteristik Nyeri Pada

Mahasiswi STIKES Bina Generasi Polewali Mandar 


\begin{tabular}{|c|c|c|c|}
\hline \multirow[t]{2}{*}{ NORES } & \multirow[t]{2}{*}{ INISIAL } & \multicolumn{2}{|c|}{ SKALA NYERI } \\
\hline & & PRE & POST \\
\hline 1 & Nn.S & 5 & 3 \\
\hline 2 & Nn.C & 5 & 3 \\
\hline 3 & Nn.W & 8 & 6 \\
\hline 4 & Nn.N & 5 & 3 \\
\hline 5 & Nn.A & 4 & 4 \\
\hline 6 & Nn.F & 4 & 2 \\
\hline 7 & Nn.W & 7 & 5 \\
\hline 8 & Nn.P & 8 & 8 \\
\hline 9 & $\mathrm{Nn} . \mathrm{O}$ & 7 & 5 \\
\hline 10 & Nn.L & 9 & 8 \\
\hline 11 & Nn.C & 9 & 8 \\
\hline 12 & Nn.Z & 9 & 8 \\
\hline 13 & Nn.R & 8 & 6 \\
\hline 14 & Nn.G & 7 & 5 \\
\hline 15 & Nn.A & 4 & 2 \\
\hline 16 & Nn.F & 5 & 3 \\
\hline 17 & Nn.W & 6 & 6 \\
\hline 18 & Nn.P & 7 & 6 \\
\hline 19 & Nn.O & 4 & 3 \\
\hline 20 & Nn.L & 7 & 5 \\
\hline
\end{tabular}

Sumber :Data Primer 2017

Berdasarkan data dibawah ini menujukkan bahwa nyeri dismenore dari 20 responden didapatkan bahwa responden

Setelah diberikan relaksasi genggam jari respoden yang paling banyak adalah nyeri sedang sebanyak 9 responden $(45 \%)$ dan paling banyak adalah nyeri berat yaitu nyeri berat sebanyak 11 responden $(55 \%)$ kemudian nyeri sedang yaitu 9 responden (45\%).

nyeri ringan 7 responden(35\%) serta paling sedikit nyeri berat sebanyak 4 responden (20\%).

Tabel 4.2.3.1

Analisis Pengaruh Teknik Relaksasi Genggam Jari Dengan Nyeri Disminore Uji Paired T Test

\section{Paired Samples Test}

\begin{tabular}{|l|l|l|l|l|}
\hline Paired Differences & $\mathrm{t}$ & $\mathrm{df}$ & Sig. (2- \\
\hline
\end{tabular}




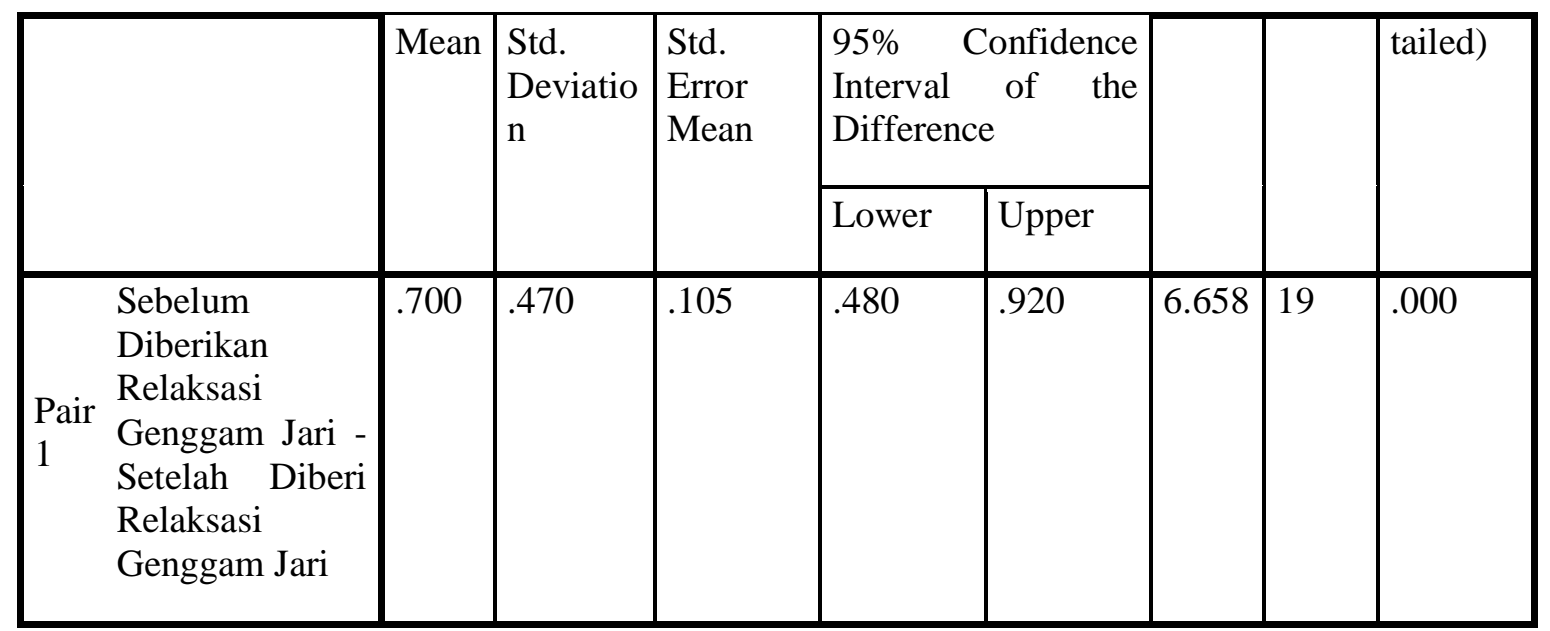

Sumber :Data Primer 2017

Pada penelitian ini hasil nilai $p$ adalah 0,000 dengan signifikasi $0,000>\alpha=0,05$ yang berarti ada pengaruh teknik relaksasi genggam jari terhadap penurunan intensitas nyeri. Sehingga dapat dikatakan bahwa dengan melakukan relaksasi genggam jari dapat menurunkan nyeri dismenore secara berarti. 
4.1 Pembahasan

\subsubsection{Instensitas nyeri sebelum dilakukan tehknik relaksasi genggam jari}

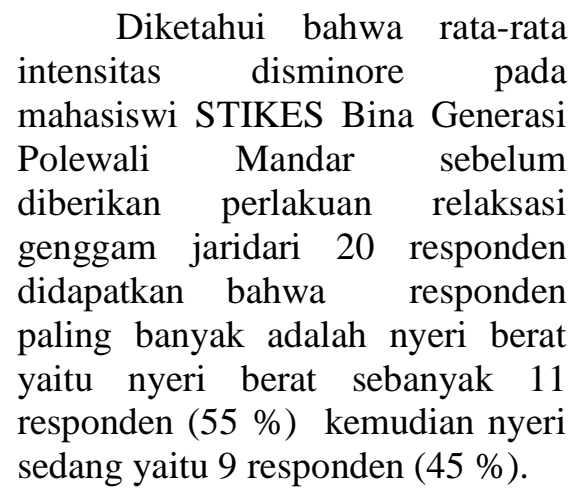

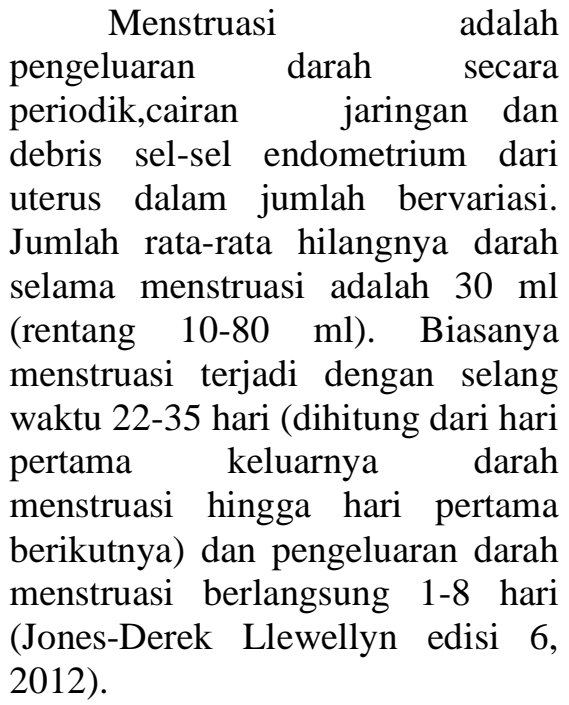

Dismenorea adalah nyeri haid yang sedemikian hebatnya, sehingga memaksa penderita untuk istirahat dan meninggalkan pekerjaan atau cara hidup seharihari untuk beberapa jam atau beberapa hari (cermin dunia kedokteran,2015)

Dismenorea primer atau Sering juga disebut sebagai dismenore sejati, intrinsik, esensial atau fungsional. Nyeri haid timbul sejak menars, biasanya pada bulanbulan atau tahun-tahun pertama haid. Biasannya terjadi pada usia 15 sampai 25 tahun dan kemudian hilang pada usia akhir 20-an atua 30-an. Tidak dijumpai kelainan alat-alat kendungan.

\subsubsection{Instensitas dismenore sesudah dilakukan tehknik genggam jari}

Namun setelah diberikan teknik relaksasi genggam jari intensitas disminore didapatkan hasil responden yang paling banyak adalah nyeri sedang sebanyak 9 responden $(45 \%)$ dan nyeri ringan 7 responden $(35 \%)$ serta paling sedikit nyeri berat sebanyak 4 responden $(20 \%)$.

Teknik mengenggam jari merupakan bagian dari teknik Jin Shin Jyutsu. Jin Shin Jyutsu adalah akupresur Jepang. Bentuk seni yang menggunakan sentuhan sederhana tangan dan pernafasan untuk menyeimbangkan energy di dalam tubuh. Tangan (jari dan telapak tangan) adalah alat bantuan sederhana dan ampuh untuk menyelaraskan dan membawa tubuh menjadi seimbang. Setiap jari tangan berhubungan dengan sikap sehari-hari. Ibu jari berhubungan dengan perasaan khawatir, jari telunjuk berhubungan dengan ketakutan, jaritengah berhubungan dengan kemarahan, jari manis berhubungan dengan kesedihan, dan jari kelingking berhubungan dengan rendah diri dan kecil hati (Hill, 2011)

\subsubsection{PengaruhTeknikRelaksasiGengga mJari}

Hasil analisis data tentang pengaruh Teknik Relaksasi Genggam Jari sebelum dan sesudah menunjukkan nilai signifikasi (p) 0,00 artinya $\mathrm{p}<\alpha$, dengan nilai $<$ 0,05 yang berarti ada pengaruh yang bermakna sebelum dan sesudah pemberian relaksasi genggam jari.

Nyeri dismenore dari 20 responden didapatkan bahwa responden paling banyak adalah nyeri berat yaitu nyeri berat sebanyak 11 responden (55 \%) kemudian nyeri sedang yaitu 9 responden $(45 \%)$. 
Setelah diberikan relaksasi genggam jari respoden yang paling banyak adalah nyeri sedang sebanyak 9 responden (45\%) dan nyeri ringan 7 responden(35\%) serta paling sedikit nyeri berat sebanyak 4 responden (20\%).

Sesuai dengan penelitian yang dilakukan oleh Sri Mardina dengan judul "Efektifitas Teknik Relaksasi Genggam Jari dan Nafas Dalam Dalam Penurunan Nyeri Disminore "hasil penelitian denang nilai $p$ 0,00 dikatakan ada pengaruh terhadap penurunan nyeri dismonore, dalam penelitian ini dengan menggenggam jari akan menghasilkan impuls yang dikirimmelaluiserabutsarafaferen non nosiseptor. Serabutsaraf non nosiseptor mengakibatkan tertutupnya pintugerbang thalamus sehingga stimulus yang menuju korteks serebri terhambat sehinggai ntensitas nyeri dapat berkurang. Menurut Hill (2011) dengan mengenggamjari dipercayadapatmembukaaliranener gi yang terkunci yang disebutsafety energy locks sehinggaaliran energy menjadilancar.

$\begin{array}{ccc}\begin{array}{c}\text { Tindakan } \\ \text { dipandang }\end{array} & \text { relaksasi } & \text { dapat } \\ \text { sebagai } & \text { upaya }\end{array}$ pembebasan mental dan fisik dari tekanan dan stress.dengan relaksasi, klien dapat mengubah persepsi terhadap nyeri. kemampuannya dalam melakukan relaksasi fisik dapat menyebabkan relaksasi mental. Relaksasi memberikan efek secara langsung terhadap fungsi tubuh, seperti :Penurunan tekanan darah, nadi , dan frekuensi pernafasan, penurunan komsumsi oksigen oleh tubuh Penurunan ketegangan otot, meningkatkan kemampuan konsentrasi, menurunkan perhatian terhadap stimulus lingkungan (Ns. Anas Tamsuri, S.kep 2007).

Dari penelitian ini penulis mengambil benang merah bahwa dengan melakukan teknik relaksasi genggam jari membuat saraf eferen yang menjadi pengantar nyeri menjadi terhambat ke pintu gerbang thalamus dan kepusat nyeri korteks serebri, sehingga dengan melakukan teknik relaksasi tersebut secara konsisten maka dapat menurunkan nyeri disminore yang merupakan masalah gangguan rasa nyaman yang dirasa kaumwanita.

Penanganan

dapatdiberikanuntukmengurangi

dismenoreadalah dengan pemberian terapi farmakologi seperti pemberian obat analgetik, terapi hormonal, terapidenganobatnon steroid anti prostaglandin dan dilatasikan alis servikalis. Selainituterapinon farmakologisjugadiperlukanuntukm engurangidismenore.Salah

satunyadenganmenggunakanteknikr elaksasi.Teknikinididasarkankepad akeyakinanbahwatubuhberesponpa daansietas yang merangsang pikiran karena nyeri atau kondisi penyakitnya. Dalam penatalaksanaan dismenore, akan lebih efektif jika mengkombinasikan dua ataulebihmetode non-farmakologis yang ada. Salah satu jenis kombinasi metode nonfarmakologis yang dapat kita terapkan yaitu kombinasi relaksasi genggam jari dan napas dalam. Kedua metode ini merupakan metode yang sederhana dan dari beberapa penelitian mengatakan bahwa metode ini efektif dalam mengurangi nyeri.

\section{KESIMPULAN DAN SARAN Kesimpulan}

Dari hasil pengolahan data penelitian yang telah di lakukan, diperoleh kesimpulan bahwa :

1. Tingkat nyeri dismenore setelah diberikan teknik relaksasi genggam jari intensitas disminore didapatkan hasil responden yang paling banyak adalah nyeri sedang sebanyak 9 responden $(45 \%)$ dan nyeri ringan 7 responden $(35 \%)$ serta paling sedikit 
nyeri berat sebanyak 4 responden (20\%).

2. Tingkat nyeri dismenore sebelum diberikan perlakuan relaksasi genggam jaridari 20 responden didapatkan bahwa responden paling banyak adalah nyeri berat yaitu nyeri berat sebanyak 11 responden $(55 \%)$ kemudian nyeri sedang yaitu 9 responden $(45 \%)$.

3. Pengaruh relaksasi genggam jari terhadap penurunan nyeri disminoredidapatkan nilai signifikasi dengan nilai signifikasi (p) 0,000; artinya $\mathrm{p}<\alpha$, dengan nilai $<0,05$, yang berartiada pengaruh pemberian relaksasi genggam jari dismenore terhadap penurunan nyeri pada mahasisswi

\section{A. Rekomendasi}

1. Tehnik relaksasi genggam jari adalah merupakan suatu bentuk tindakan keperawatan, yang dalam hal ini perawat mengajarkan kepada klien. Maka kita harus berusaha untuk menerapkan tehnik non farmakologik tersebut kepada pasien khususnya yang mangalami dismenore.

2. Untuk menambah pengetahuan khususnya tentang nyeri dismnore untuk pembaca harus lebih mencari secara spesifik tentang relaksasi genggam jari.

3. Diharapkan lebih banyak menambah besar sampel penelitian dan menambah daerah penelitian sehingga dapat terjangkau sasaran penelitian untuk mengetahui sejauh mana pengarih relaksasi genggam jari terhadap penurunan intensitas nyeri pada mahasiswi, selain itu juga perlu penelitian lanjutan dengan cara terapi non farmakologis yang lain.

\section{DAFTAR PUSTAKA}

A. Azis Alimul Hidayat 2007. Riset keperawatan dan Tekhnik Penulisan Ilmiah. Edisi 2, Salemba Medika : Jakarta

Agus Riyanto, SKM., M, Kes 2011. Aplikasi metodologi penelitian kesehatan. Yogyakarta : Nuba Medika
Asmadi. (2008). Teknik prosedural keperawatan: Konsep dan aplikasi kebutuhan dasar klien. Jakarta: SalembaMedika.

Bobak, Lowdermilk, Jansen. 2013. Buku Ajar Keperawatan Maternitas. Edisi 4.

Jakarta : EGC.

Chalis karim anton, PharmD, Mph. 2015. Dysmenorrhea.[cited 2016 feb 4] avaible from: http:// emedicine.medscape.com/article/2538 12-overview, Penelitian, pengembangan. 2013. Riset kesehatan dasar.h.222

Dr. Eleanor Bull \& Dr. Graham Archard (2007). Simple Guides, Nyeri Punggung, Jakarta : Erlangga

Dahlan, M. Sopiyudin, 2012. Langkah Langkah Membuat Proposal Penelitian Bidang Kedokteran Dan Kesehatan, Edisi Kedua, Jakarta : Sagung Seto.

Erlysita Lammarisi, A.Md. Keb., dkk, (2015). HANBOOK Klinik Keperawatan Dan Kebidanan. Jakarta : Bhafana publising

Hidayat, A.A, 2007. Metode Penelitian Keperawatan dan Teknik Analisis Data, Salemba Medika, Jakarta.

Hutasoit, A.S. 2002. Panduan Praktis Aromatherapy Untuk Pemula. Jakarta: PT

Gramedia Pustaka Utama.

Hill, R. Y. (2011). Nursing from the insideout:Living and nursing from the highest point of your consciousness. London: Jones and Barlett Publishers

Musrifatul Uliyah \& A. Aziz Alimul Hidayat (2009), keterampilan dasar praktik klinik. Jakarta : Salemba Medika

Morgan, G., \& Hamilton, C. (2009). Obstetri \&ginekologi panduan praktik. Jakarta: EGC. 
Norwitz, Errol dkk. (2007). At a Glance Obstetri \& Ginekologi Edisi 2. Jakarta: Erlangga.

Ns. Anas Tamsuri, S.kep (2007). Seri kebutuhan dasar manuasia, Konsep dan penatalaksanaan nyeri. Jakarta : Kedokteran EGC

Nasir, Abd., Muhith, Abdul., \& Idaputri, ME. (2011). Metodologi Penelitian Kesehatan: Konsep Pembuatan Karya Tulis dan Thesis Untuk Mahasiswa Kesehatan Yogyakarta: Nuha Medika

Prof. Dr. Soekidjo Notoatmodjo, 2007. Metodologi Penelitian Kesehatan. Jakarta: PT Rineka Cipta

Prof. Dr. Ida Bagus Gde Manuaba,SpOG.,(2015) Memahami Kesehatan Reproduksi Wanita. Jakarta : Arcan

Sarwono, P. (2014). Ilmu Kandungan. Jakarta : PT Gramedia

Saryono, SKp. M.Kes 2010 Metodologi Penelitian Kesehatan. MITRA CENDEKIA PRESS; Yogyakarta.

Sugiyono. 2009. Metode Penelitian Kuantitatif, Kualitatif dan $R \& D: C V$ Alfabeta

Sopiyudin dahlan, 2010. Langkah-Langkah membuat proposal penelitian bidang kedokteran dan kesehatan Edisi 2, Jakarta : Sagung Seto

Wiknjosastro, Hanifa. (2014). Ilmu Bedah Kebidanan. Jakarta: Yayasan Bina Pustaka Sarwono Prawirohardjo. 